\section{Cureus}

Received 12/26/2012

Review began 12/27/2012

Published 02/16/2013

\section{Copyright 2013}

Cunningham et al. This is an open access article distributed under the terms of the Creative Commons Attribution License CC-BY 3.0., which permits unrestricted use, distribution, and reproduction in any medium, provided the original author and source are credited.

\title{
Undescended Testis: The Risk Always Lives
}

\author{
John D. Cunningham ${ }^{1}$, Akintunde R. Akinleye ${ }^{2}$ \\ 1. Department of Surgery, Overlook Medical Center, New Jersey; Department of Surgery, Summit Medical \\ Group, Berkeley Heights, New Jersey 2. Department of Hematology and Oncology, Westchester Medical \\ Center
}

$\square$ Corresponding author: Akintunde R. Akinleye, docakin@gmail.com Disclosures can be found in Additional Information at the end of the article

\section{Abstract}

The testes develop in the abdomen and descend during the third trimester into the scrotum. The testicle can be arrested anywhere during its descent or it can migrate into an abnormal position. Undescended testis, otherwise known as cryptorchidism, is a well-described disorder with a spectrum of complications ranging from torsion to necrosis, infertility, and atrophy. The risk of developing testicular cancer in an undescended testicle has been well-documented, as high as 32 times the general population if the testicle is not brought down before the age of 12 . In clinical practice, surgical exploration for the testicle and definitive fixation in the scrotum is warranted at age two to three if it fails to descend to the normal position, with clinical success rate of $90 \%$. However, the problem with an undescended testicle arises when surgical exploration is negative, and the usefulness of other approaches, including imaging tests, in this setting is not clearly established. We report a case of a 45 year-old man with history of undescended left testicle diagnosed at birth, and repeated negative surgical explorations presenting with symptomatic pelvic mass, and eventually diagnosed with testicular tumor. This case highlights the potential difficulty in establishing this diagnosis despite the generally favorable outcomes with orchiopexy. Given its high prevalence, testicular neoplasm must be included in the differential diagnosis of patients with a history of an undescended testicle who present with an acute abdomen. Surgical resection without pelvic lymph node dissection is the standard of care for an abdominal testicle found at exploration.

Categories: General Surgery, Oncology

Keywords: torsion, surgical exploration, undescended testis, cryptorchidism, orchiopexy, seminoma

\section{Introduction}

The testes develop in the abdomen and descend during the third trimester into the scrotum. This typically occurs during 28-32 weeks of intrauterine life. The testicle can be arrested anywhereduring its descent or it can migrate into an abnormal position. The most common locations of anectopic or undescended testis are high scrotal (50\%), canalicular (20\%), and abdominal (10\%). Cryptorchidism is present in approximately $5 \%$ of newborns and this rate is higher in preterminfants. It is the most common birth abnormality in males [1, 2]. This rate decreases to $1 \%$ by the endof the second year. Therefore, most physicians do not recommend treatment until 12 months of age. There are several potential problems associated with an undescended testicle. Commoncomplications include torsion, necrosis, infertility and atrophy. There is also an association between cryptorchidism and testicular cancer. In clinical practice, surgical exploration for the testicle and definitive fixation in the scrotum is warranted at age 23 if it fails to descend to the normal position.

\section{Case Presentation}




\section{Cureus}

A previously healthy 45 year old Caucasian male presented to his primary physician with nightsweats associated with the acute onset of LLQ abdominal pain. He described the pain as sharp innature and radiating to the groin. He denied fevers, nausea, vomiting, change in bowel habits. He reported no sick contacts or recent travel. He had no complaints of fatigue, pruritus, weight loss, or urinary symptoms. The patient had been diagnosed with an undescended left testicle at birth. He had a negative groin exploration at the age of 2 years. He subsequently presented two years ago with urinary symptoms. A CT scan at that time showed a $3 \mathrm{~cm}$ mass in the left pelvis. He underwent surgical evaluation for the mass. The final pathology revealed reactive lymph nodes with the largest node measuring $3.8 \mathrm{~cm}$. His past medical history was also significant for borderline hypertension and anxiety. He was on no medications.

Physical examination revealed a well-nourished male. The abdomen was non-distended and a lower midline scar was present. Bowel sounds were present. There was tenderness in the LLQ without guarding or rebound. He had bilateral inguinal scars, an absent left testicle and a normal right testicle.Laboratory values were significant for a white blood cell count was $11.2 \mathrm{X}$ $10^{3} \mu \mathrm{L}$ with no shift. ACT scan of the abdomen/pelvis revealed an $8 \times 7 \mathrm{~cm}$ lobulated, pedunculated mass arising just anterior and superior to the bladder and extending into the right pelvis. There was an air density in the mass (Figure 1). The patient's pain had resolved by the time he got to the emergency room. He subsequently underwent an exploratory laparotomy.

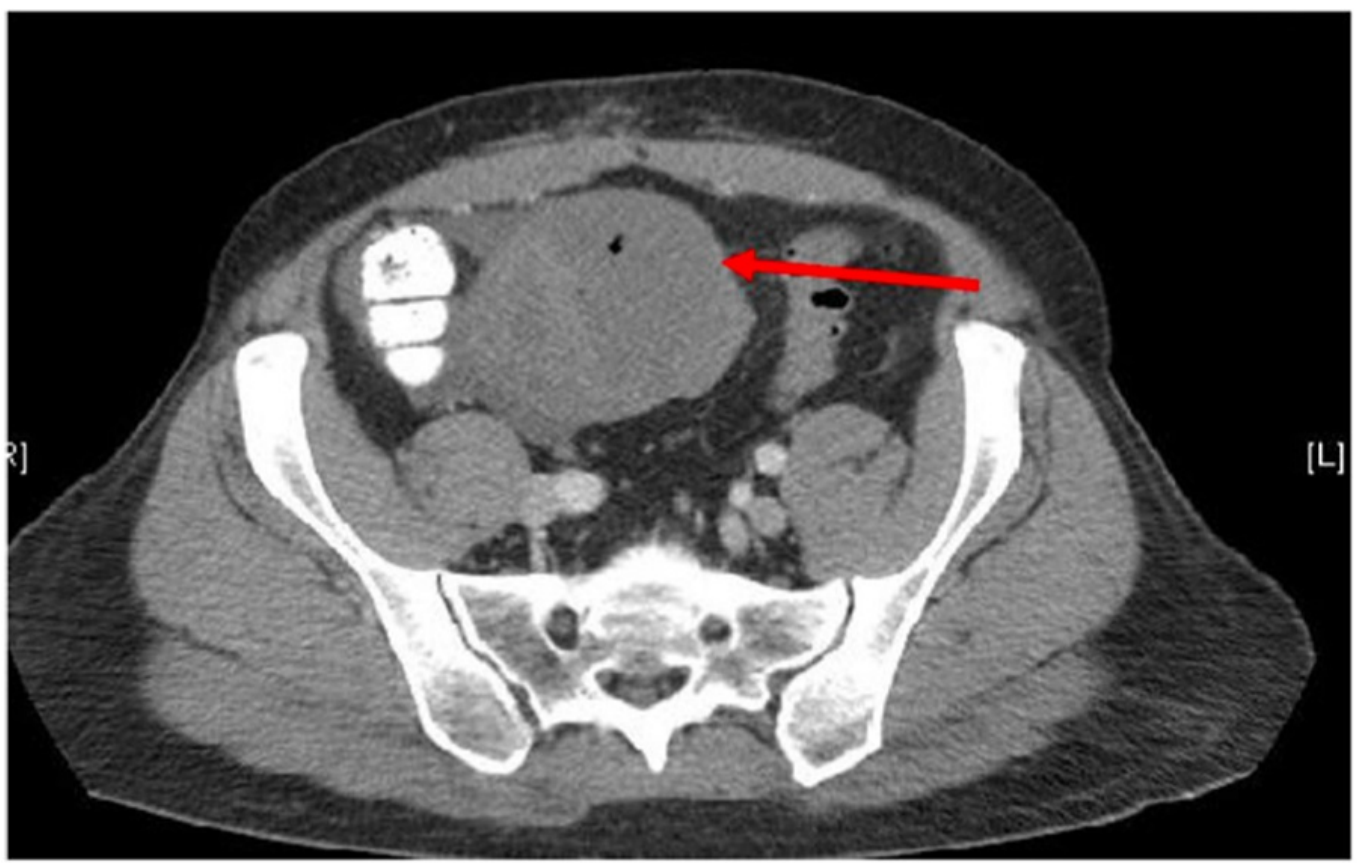

FIGURE 1: Computed tomography image demonstrating a pelvic mass anterior and superior to the bladder

Question: What is the mass?

1. Infarcted colonic epiploica

2. Hemorrhagic left testicular mass

3. Perforated colonic diverticula with abscess 


\section{Transitional cell tumor of the bladder}

Answer: Hemorrhagic left testicular mass.

The operative findings were consistent with a hemorrhagic testicular mass and the tumor was resectedat the base. Histopathology confirmed the mass to be an $11 \times 9 \times 7 \mathrm{~cm}$ predominantly necrotic andhemorrhagic neoplasm, covered by a thin capsule, containing infarcted tubules. The tumor was infiltrated by CD45 positive small lymphocytes, consistent with definitive diagnosis of seminoma. There was no evidence of lymphovascular invasion. The patient's metastatic work up was normal. Tumor markers drawn preoperatively were normal. After a routine recovery, he was discharged on postoperative day 3. His 6-month follow-up CT imaging revealed no residual or recurrent tumor.

\section{Discussion}

The absence of a testicle in a newborn warrants investigation. There is a spectrum of potential problems associated with an undescended testicle ranging from torsion, necrosis, infertility andatrophy. Most surgeons will wait until the age of two years to see if the testicle will descend on its own. If the testicle has not descended by two years, a groin exploration is warranted. Most surgeons will not do any imaging prior to this [3]. The vast majority (over 90\%) of the testicles will be found at the time of groin exploration [3]. An orchiopexy is the procedure of choice. Orchiopexy results in a 95\% anatomical success rate and has a very low complication rate [1-4].The non-operative management of an undescended testicle includes the use of hormonal therapy. The two most common therapies are hCG and GnRH. Their efficacy is estimated to be $20 \%$ and as many as $20 \%$ of undescended testicles may re-ascend after the discontinuation of therapy [2]. There are also questions of the use of these hormones in infants and a late term effect on spermatogenesis [2].

The problem with an undescended testicle arises when the groin exploration is negative at age 2-3 years. Imaging should be done to determine if there is a testicle on that side and to determine thelocation of the testicle. The imaging test of choice is ultrasonography (US) and CT scan is reserved for those patients who have a negative US of the abdomen and pelvis [2, 3]. If the testicle is identified on the imaging studies, orchiopexy is indicated $[1,4]$. If the testicle is not identified, the next step is less clear. Patients can undergo exploration because the risk of developing a cancer in the undescended testicle is much higher than in a testicle that has descended [1, 4]. The above described patient had two negative explorations. Agenesis of the testicle would be the most likely explanation for this outcome.The risk of developing a testicular cancer in an undescended testicle has been well-documented [1-4]. The risk appears to vary depending upon the treatment of the undescended testicle. The association of cryptorchidism with testicular cancer is estimated to be approximately five times the general population $[1,4]$. This increased rate can be reduced if the testicle is brought down before the age of 12 [1-4]. If the testicle is not brought down before the age of 12 , the risk of cancer in the testicle can be 32 times the general population [1].

The principal reason to do an orchiopexy after the age of twelve is to make it easier for the patient and physician to follow the testicle in the scrotum. The cancer risk for an undescended testis peaks in the third and fourth decades of life [4]. A testicular neoplasm should be in the differential diagnosis of a patient who presents with an abdominal/pelvic mass with a history of an undescended testicle. The most common type of tumor in an undescended testicle is a seminoma [1-4]. The explanation for the increased risk of cancer in an undescended testicle seems to be related to temperature $[1,4]$. There appears to be a time period of exposure to the increased temperatures that is crucial to confer this increased risk. As mentioned, the risk of cancer in an undescended testicle increases if it is not brought down into the scrotum and if it is not brought down by age 12 [1]. The changes that occur in the testicle at the time of 
puberty may be affected by the elevated temperature and this may be the cause for the increased risk of malignancy $[1,4]$.

The treatment for an abdominal testicle found at exploration for an acute surgical presentationis resection. There is no role for pelvic lymphadenectomy since the testicle never descended through the pelvis and into the inguinal canal. The use of chemotherapy is dependent upon the stage of the tumor [5].

\section{Conclusions}

The risk of developing a cancer in an undescended testicle is much higher than in the general population. The management of undescended testis after repeatedly negative explorations is not clearly established. Given its high prevalence, testicular neoplasm must be included in the differential diagnosis of patients with a history of an undescended testicle who present with an acute abdomen.

\section{Additional Information \\ Disclosures}

Human subjects: Consent was obtained by all participants in this study. Conflicts of interest: In compliance with the ICMJE uniform disclosure form, all authors declare the following:

Payment/services info: All authors have declared that no financial support was received from any organization for the submitted work. Financial relationships: All authors have declared that they have no financial relationships at present or within the previous three years with any organizations that might have an interest in the submitted work. Other relationships: All authors have declared that there are no other relationships or activities that could appear to have influenced the submitted work.

\section{References}

1. Darzi AA, Aliramaji A, Ramezani MS: Unresolved abdominal mass in an adult cryptorchidtestis: a case report. Int J Gen Med. 2010, 3:395-398. 10.2147/IJGM.S15658

2. Ritzen EM: Undescended testes: a consensus on management. Eur J of Endocrinol. 2008, 159:87-90. 10.1530/EJE-08-0181

3. Williams EV, Apparma T, Foster ME: Management of the impalpable testis: a six year review together with a national experience. Postgad Med J. 2001, 77:320-322.

10.1136/pmj.77.907.320

4. Pettersson A, Richiardi L, Nordenskj old A, et al: Age at surgery for undescended testis and risk of testicular cancer. N Engl J Med. 2007, 356:1835-1841. 10.1056/NEJMoa067588

5. Herrinton LJ, Zhao W, Husson G: Management of cryptorchism and risk of testicular cancer . Am J Epidemiol. 2003, 157:602-605. 10.1093/aje/kwg012 